\title{
Sleep Difficulties and the Development of Depression and Anxiety: A Longitudinal Study of Young Australian Women
}

Melinda L. Jackson ${ }^{1,2}$, Ewa M. Sztendur ${ }^{3}$, Neil T. Diamond ${ }^{3}$, Julie E. Byles ${ }^{4}$, Dorothy Bruck ${ }^{1}$

${ }^{1}$ Psychology Discipline, College of Arts, Victoria University, Melbourne, Australia

${ }^{2}$ Melbourne School of Psychological Sciences, The University of Melbourne, Parkville, Melbourne, Australia

${ }^{3}$ ESQUANT Statistical Consulting, Melbourne, Australia

${ }^{4}$ Research Centre for Gender, Health and Ageing, University of Newcastle, Newcastle, Australia

\section{Corresponding author:}

Dr Melinda L. Jackson

Melbourne School of Psychological Sciences, The University of Melbourne,

Victoria, Australia 3010.

Phone: (613) 90356129 Fax: (613) 93476618

Email: melinda.jackson@unimelb.edu.au 


\begin{abstract}
Purpose: Previous longitudinal studies have demonstrated that poor sleep may precede depression and anxiety. The current study examined the association between self-reported sleeping difficulties and new onset depression and anxiety in young women.

Methods: A nationally representative sample of 9,683 young women from the Australia Longitudinal Study of Women's Health was analyzed. Women were surveyed in 2000 (aged 22 to 25 years), 2003, 2006 and 2009. Generalized estimating equations were used to examine the association between sleeping difficulties in 2000 and new-onset depression (excluding postnatal depression) and anxiety at each subsequent survey.

Results: Significant increased risk of new onset depression $(\mathrm{OR}=2.6$ in 2003; $O R=4.4$ in 2006; $\mathrm{OR}=4.4$ in 2009) and anxiety $(\mathrm{OR}=2.4$ in 2006; $\mathrm{OR}=2.9$ in 2009) was found at each follow-up survey in women who reported sleeping difficulties “often” in 2000.

Conclusion: Further research is needed to uncover the mechanisms underlying the link between sleep problems and mental health.
\end{abstract}

Keywords: sleep disturbance; depression; anxiety; women; insomnia; longitudinal study 


\section{Introduction}

Depression is one of the leading global burdens of disease, and is estimated to be one of the top three health concerns by 2020 (Murray and Lopez 1997). In Australia, depression and anxiety contribute the largest proportion of burden of disease for women, accounting for around $10 \%$ of the total female burden (Begg et al. 2007). In particular, the incidence of depression in young women is three times greater than in young men, and it is the leading cause of morbidity in young Australian women (Carr-Gregg et al. 2003).

Given this widespread disease burden, it is important to identify possible underlying triggers or indicators of the increasing prevalence of mental illness in our society. Many risk factors for mental illness have been identified in addition to female gender, such as poor coping strategies, genetic factors, negative cognitive style, and an adverse response to stress (Spasojević and Alloy 2001; Dobson and Dozois 2011; Drake et al. 2004). Sleep disturbance has also been highlighted as a potential risk factor for depression (Baglioni et al. 2011). Insomnia itself is extremely prevalent, with approximately $30 \%$ of adults reporting one or more symptoms of insomnia at any given time (Dodge et al. 1995). An estimated 6\% of the population meet the DSM-IV criteria for Primary Insomnia (Ohayon 2002), defined as difficulties initiating or maintaining sleep, or nonrestorative sleep, persisting for at least four weeks. Of relevance, female gender is also a risk factor for insomnia. Young adult women are almost twice as likely to experience poor sleep than young men, and this risk increases with age (Byles et al. 2003). Specifically in women, poor sleep is associated with a number of negative health outcomes (Leineweber et al. 2003; Blackwell et al. 2006). Thus, young women appear to be a particularly vulnerable group to both insomnia and depression. 
Bouts of insomnia are often reported in patients with depression, and often precede the onset of depressive episodes. Large population studies have found that distinct symptoms of insomnia separately predicted reported (Jansson-Fröjmark and Lindblom 2008; Szklo-Coxe et al. 2010), and incident treatment for (Salo et al. 2012), depression at 3 to 4 years follow up, after controlling for baseline psychological distress and anxiety in addition to age, sex, socioeconomic status, night/shift work, health behaviors, and physical health. Other studies, however, have failed to find an association between insomnia and depression over time (Neckelmann et al. 2007). A recent meta-analysis revealed a two-fold increased risk of new incidences of depression in those with insomnia at baseline (Baglioni et al. 2011). While there is less evidence for the relationship between sleep disturbance and anxiety, some studies have found that chronic insomnia predicted first onset of anxiety (Jansson-Fröjmark and Lindblom 2008; Neckelmann et al. 2007; Breslau et al. 1996) and panic disorder (Weissman et al. 1997). One of the limitations of these studies is that the majority of them report combined odds ratios values for both men and women. Therefore these studies lack generalizability of their findings with respect to gender.

These previous studies have examined associations between clinically-diagnosed insomnia and mental health outcomes, however, subjective sleep complaints may also be clinically useful and accurate. Subjective sleep measures are highly correlated with objective measures of sleep, even in depressed individuals (Armitage 1997). Even at the symptoms level, sub-clinical subjective sleep complaints have also been found to precede episodes of depression (Gillin, 1998; SzkloCoxe et al. 2010). Thus, examining self-reported sleeping problems is important to study in this context. 
The prevalence of insomnia and mental illness varies across the life span (Byles et al. 2003; Wittchen et al. 1994; Jorm 2000). Studies that have examined associations between insomnia and mental health outcomes in older cohorts have found increased risk of depression (Yokoyama et al. 2010; Roberts et al. 2000), and associations with poorer quality of life in women (Byles et al. 2005). Less research has been conducted in younger age groups, who are at particular risk of insomnia and alterations in circadian timing due to developmental and social influences (Colrain and Baker 2011). This age group also presents an important stage of life where early interventions or treatment of sleeping problems may have significant clinical implications. Studies of adolescents (Roane and Taylor 2008; Roberts et al. 2002; Roberts and Duong 2013) and young adults (Breslau et al. 1996; Buysse et al. 2008) have found that those with selfreported sleeping difficulties had an increased risk of subsequent depression, controlling for gender and baseline depression. While the majority of these studies have only used short follow up periods, there is some evidence that risk of mental health concerns may also increase over longer periods of sleeping difficulties (Buysse et al. 2008; Chang et al. 1997. Examining the trajectory of the link between sleeping problems and mental health outcomes over longer time periods will allow us to determine whether these associations worsen over time, or vary with age, thus more deeply informing our understanding of this phenomenon and intervention efforts.

The aim of the current study was to examine potential predictive relationships between selfreported sleeping problems and depression and anxiety over nine years in a large community sample of young Australian women. The prevalence of depression and anxiety, and the 
relationship between sleeping difficulties and depression and antidepressant use across surveys, was also explored.

\section{Methods}

\section{Data collection}

Data from a longitudinal cohort study (Australian Longitudinal Study on Women's Health, ALSWH), which is designed to track the health of women over a period of up to 20 years, was used. The current study focused on the young cohort, which included women aged 22 to 27 years in 2000; the year of the first data point in the current study. The ALWSH sample was drawn from the database of the Health Insurance Commission, the universal provider of basic health insurance, which involves all women in Australia (including women who reside in Australia but who do not have permanent residency status). The participants in the survey are broadly representative of the Australian population, however, women from rural and remote areas were sampled at twice the rate of women in urban areas. The surveys collected demographic and health data using a wide range of questionnaire items measuring physical, social, mental health status, exercise and diet, and healthcare use (including use of medications). All women had completed comprehensive health surveys in 1996, 2000, 2003, 2006 and 2009; there was no question regarding depression in the 1996 survey therefore only the last four collection years were used in the current analyses. The sample consisted of 9,683 young women at the 2000 survey, 9,078 women in the 2003 survey, 9,140 in the 2006 survey and 8,196 women responded in 2009. The actual survey questions can be viewed on the Internet (www.alswh.org.au/forresearchers/surveys), along with details of where specific questions have been validated or used previously (Australian Longitudinal Study on Women's Health 2011). 


\section{Measures}

\section{$\underline{\text { Psychological variables }}$}

A number of items relating to mental health status were assessed. Respondents were asked "In the last 3 years, have you been diagnosed or treated for a) depression (not postnatal) or b) anxiety disorder?" Respondents were also asked "In the past 12 months, have you had c) depression or d) episodes of intense anxiety?" rated on a 4-point scale ranging from 0 (never), 1 (rarely), 2 (sometimes), and 3 (often).

\section{Sleeping difficulty}

One item relating to sleeping difficulty asked participants whether they had experienced sleeping difficulties in the last 12 months, rated on a 4-point scale ranging from 0 (never), 1 (rarely), 2 (sometimes), and 3 (often). Sleeping difficulties "often" was used as the independent variable.

\section{Demographics and selected variables}

A question regarding education level was categorized across seven levels (no formal qualification, Year 10, Year 12, trade/apprenticeship, certificate/diploma, university degree, and higher university degree). The frequency of binge-drinking question asked how often respondents had five or more standard drinks of alcohol on one occasion categorized across 5 levels ("never" to "more than once a week"). History of abuse (physical, emotional or sexual, or harassment) was also recorded and score dichotomously (yes or no). One question concerning body weight dissatisfaction asked "How much would you like to weigh now?" and the 6 options ranged from 1 (happy as I am), 2 (1-5 kg more), 3 (over $5 \mathrm{~kg}$ more), 4 (1-5 kg less), 5 (6-10 kg less), to 6 
(over $10 \mathrm{~kg}$ less). A dichotomous variable was obtained by combining the first five options into one category, and the last option became a second category; thus, this variable only related to dissatisfaction with being $10 \mathrm{~kg}$ over their current weight. The above four variables were included in the adjusted regression model as they had been found in a previous study using this dataset (2003 survey) to make a significant contribution to sleep difficulty when a range of other variables (including depression and anxiety) were controlled (Bruck and Astbury 2012). Respondents were also asked whether they had used different types of medication ("prescription medication for your nerves", "prescription medication to help you sleep" and "prescription medication for depression") over the past 4 weeks.

\section{Statistical Analyses}

Statistical analyses were performed using R (R Foundation for Statistical Computing, 2008). Prevalence statistics were generated for each of the variables (sleeping difficulty, depression status, anxiety status) at each survey. An area-weighting variable was used to adjust for the oversampling of women in rural and remote areas, to provide a more accurate representation of the prevalence rates of Australian population.

Generalized estimating equations (GEE) were used to examine the association between selfreported sleeping difficulties in the last 12 months at the 2000 survey and a report of a diagnosis in the past 3 years of a) depression (excluding postnatal depression) and b) anxiety at each subsequent survey. The comparison group was women who reported sleeping difficulties but did not report a diagnosis of depression or anxiety in 2003, respectively (i.e. those women from 2000 who continued to report sleeping difficulties but did not report any mental health concerns). 
Adjusted models were also fitted using education level, history of abuse, dissatisfaction with body weight and binge drinking reported in 2000 as covariates, as there variables were significantly associated with sleeping difficulties in our previous analysis of this database (Bruck and Astbury 2012). Women who reported a previous diagnosis or symptoms (in last 12 months "often") of depression or anxiety at the 2000 survey, with or without co-existing sleeping difficulties, were excluded from the depression and anxiety analyses. Additionally, women who reported antidepressant use at the 2000 survey were also excluded from the analyses, leaving 5,705 in the final sample.

The method of GEE was chosen as it is the most convenient and appropriate method to analyse the longitudinal data, particularly given that the dependent variable was dichotomous. GEE has a number of appealing properties: It is almost as efficient as those based on the full likelihood, and it is robust to miss-specification of the within person correlations. However, it should be emphasized that for GEE to be unbiased, missing data should be missing completely at random (MCAR). If the data is only missing at random (MAR), that is the probability of missingness depends on observed variables, then the GEE analysis will be biased. To overcome this limitation, multiple imputation was carried out using the mice package (Van Buuren and Groothius-Oudshoorn 2011) in R to produce 25 imputed data sets. For the imputations, binary variables were imputed using logistic regression and ordinal variables were imputed using proportional odds logistic regression, and each variable was used as the response with the other variables as explanatory variables, and 25 iterations were performed. The GEE analysis was then repeated for each imputed data set and the results were combined using Rubin's method, where the final estimate for each parameter was the mean estimate over the imputed analyses, and the 
standard error was the square root of a weighted average of the within-analyses variances and the variance of the estimates between analyses.

\section{Results}

\section{$\underline{\text { Response rates }}$}

The response rates were $68.0 \%(\mathrm{~N}=9,683), 63.7 \%(\mathrm{~N}=9,078), 64.2 \%(\mathrm{~N}=9,140)$ and $57.6 \%$ $(\mathrm{N}=8,196)$ for years 2000, 2003, 2006 and 2009 respectively.

\section{$\underline{\text { Sample characteristics }}$}

Sample characteristics are presented in Table I. The majority of the respondents in 2000 were not married, had tertiary education, and had a professional or clerical/ service worker occupation. The prevalence figures for sleeping difficulties, depression diagnosis and symptoms, anxiety diagnosis and symptoms, and comorbid depression and anxiety for all women who responded at each survey are displayed in Table II. Sleeping difficulties "often" were reported by $10.1 \%$ of the sample in 2000, and this prevalence remained steady across subsequent surveys. Depression diagnosis increased steadily across the 4 surveys, from $11.6 \%$ in 2000 to $17.7 \%$ in 2009 . A gradual increase in self-reported anxiety diagnosis across each survey, from $4.7 \%$ to almost $10 \%$, was also observed. A small proportion (2.9\%) of women reported both a depression and anxiety in 2000, and this prevalence also increased slightly across each survey, to $6.8 \%$ in 2009 .

Figure 1 depicts the percentage of women who reported a depression diagnosis and antidepressant use, as a function of the frequency of sleeping difficulties, at each survey. The prevalence of depression increased with increasing sleeping difficulties. For example, in 2003 
$18.5 \%$ of women with sleeping difficulties "often" reported a diagnosis of depression, compared to only $3.6 \%$ who reported sleeping difficulties rarely. This pattern was similar across all three surveys. The prevalence of antidepressant use reported by women self-reporting a depression diagnosis ranged from $29 \%$ to $47 \%$ in the 2003 and 2006 surveys, and was stable across sleeping difficulty categories (question regarding antidepressant use was not asked in 2009). There was a significant proportion of women who reported a depression diagnosis and no or rare sleeping problems across all three surveys (6.3\% in 2003; 8.8\% in 2006 and $15.2 \%$ in 2009).

\section{$\underline{\text { GEE analysis }}$}

Results from the GEE unadjusted model indicated that young women who reported sleeping difficulties (but no depression) in 2000 had an increased risk of developing depression in subsequent years (Table III). The unadjusted model showed, for example, that the odds ratio (OR) of a woman reporting a diagnosis of depression in 2009 was 4.42 if she had reported sleeping difficulties 'often' in 2000 (but no depression symptoms, diagnosis or medication). These associations remained significant in the adjusted model, controlling for history of abuse, education level, body weight dissatisfaction and binge drinking reported in 2000. However, only history of abuse and education level were significantly associated, with those women having a $16 \%$ and $28 \%$ increased chance of developing depression if they reported a history of abuse or a lower education level, respectively. In addition, as the frequency of self-reported sleeping difficulties increased, so too did the risk of later depression. Similarly, risk of anxiety also increased across years in women who reported sleeping difficulties at the 2000 survey (Table IV). The OR associations were lower for anxiety than for depression, but many associations remained significant for anxiety. 


\section{Discussion}

The current study examined the risk of developing new onset depression and anxiety during a nine-year follow-up in young women who reported sleeping difficulties. Moderate to strong associations were found between frequent sleeping difficulties and self-reported diagnosis of depression and anxiety. These findings reflect and advance those of previous studies in a number of ways. Firstly, this study has assessed sleeping problems and mental health in one of the largest cohorts of young women to our knowledge. Secondly, we have examined the role of sleeping difficulties in a population who are particularly vulnerable to both insomnia and depression (i.e. young women). Thirdly, the longitudinal nature of the data allowed us to follow the time course of new episodes of depression and anxiety in women who reported sleeping difficulties at baseline over almost a decade.

Results from our GEE analysis indicated that greater subjective reports of sleeping difficulties resulted in higher ORs of reporting a diagnosis of depression. This is in line with previous studies reporting an increased risk of new onset depression in individuals with insomnia in different population groups. A meta-analysis by Baglioni et al. (2011) found a two-fold increase in depression risk in patients with insomnia; this is compared to a four-fold increased risk with frequent sleeping difficulty found in the current study. The higher ORs found in our study may reflect the population we have studied, who experience higher incidences of both depression and insomnia. Significant alterations in sleep are observed during late adolescence to young adulthood as part of the normal developmental process, including profound changes in both the timing and quantity of sleep. In isolation, these changes are not detrimental to the well-being of 
young adults, however, when combined with factors such engagement in more social activities, electronic media (Shochat et al. 2010), and other obligations (e.g. work, study, sport) (Carskadon 2002), sleep duration and quality may be reduced. Taken together, this stage of life represents a vulnerable period regarding the maturational integration of top-down control of emotional processes, and susceptibility to sleep difficulties, which together may lead to an increased risk of mental health problems (Gangwisch et al. 2010). The higher OR in the current study, however, may also be accounted for by the retrospective self-reported method used and broad assessment of sleeping difficulties in the survey. These associations require further investigation using more specific and defined measures of sleeping problems, and clinical diagnosis of depression and anxiety in order to tease these issues apart.

This study is one of the few longitudinal analyses that have examined the role of sleeping problems in the development of anxiety. Sleeping difficulties significantly predicted a selfreported anxiety diagnosis six to nine years later, with a two-fold increased risk, in line with a previous prospective analysis over three years (Breslau et al. 1996). These data are in contrast to Johnston et al. (2006) who found that prior insomnia did not predict future first-onset anxiety in a retrospective analysis. Given that this study was in adolescents, the authors suggested that cases in which insomnia precedes anxiety disorders may develop further into adulthood. Sleeping problems are often exacerbated by worry or concern about sleep, thus, it is plausible that sleeping problems initially increase anxiety specifically about sleep, which over time evolves to become more generalized anxiety. The association between sleep and anxiety is complex, and future research is needed to determine whether sleep difficulties reflect a predisposition or risk factor for new onset anxiety. 
The prevalence of frequent sleeping difficulties "often" was relatively stable across the 9 year period at around $10 \%$, similar to the prevalence of insomnia in this age group in the general community (Ohayon and Reynolds 2009; Hillman and Lack 2013). Thus, self-reported sleeping problems in the current study were reported to a similar rate as the prevalence of clinical insomnia. The subjective experience of poor sleep has also been linked to depression in previous studies (Gillin 1998; Szklo-Coxe et al. 2010), indicating that subjective measures of sleeping problems may have important clinical utility. The addition of severity categories of self-reported sleeping difficulties allowed for the examination of relationships between severity of sleeping problems and risk of depression and anxiety. Consistent with previous studies (Salo et al. 2012), as self-reported sleeping difficulty severity increased, so too did the risk of depression in the current cohort.

Despite the growing number of studies highlighting the link between insomnia and the development of depression and anxiety, we are still irresolute as to how these conditions are linked. On one hand, sleep disturbance may be a prodromal symptom, marking the onset of clinical depression or anxiety disorder. Another hypothesis is that there may be a cosusceptibility to both insomnia and depression in some individuals, but with different time courses. Sleep disturbances may represent a biological vulnerability to depression, with those who are susceptible to insomnia also having a vulnerability to depression. The time course of the two morbidities may be different, whereby insomnia appears first. 
Alternatively, sleep disturbance may play a more causative role in the development of mental health issues. A recent study in predominantly female twin pairs found that sleep duration moderated genetic influences on self-reported depressive symptoms, suggesting a geneenvironment interaction between depression and sleep duration (Watson et al., 2014). The genetic risk for depression increased in those twins who were outside of the normal sleep duration range of $7-8.5 \mathrm{~h} / \mathrm{night}$. Laboratory studies suggest that sleep loss may lead to cognitive and affective alterations that result in depressed mood (even in those who were not susceptible). For example, sleep loss undermines emotional regulation and stability (Yoo et al. 2007), and may alter neural processes that may contribute to the symptomatology of depression (Novati et al. 2008). From a cognitive perspective, sleep disturbances may alter our cognitions, resulting in a loss of control/helplessness/hopelessness. Thoughts associated with insomnia may activate similar thoughts common in depression; lying awake in the dark presents a tabula rasa for depressive rumination that may trigger a depressive episode. From a biological standpoint, insomnia may promote circadian misalignment that may contribute to decrements in diurnal mood and performance. There is recent evidence that sleep disturbance is associated with an increased inflammatory state (Madje and Krueger 2005). Patient populations (Motivala et al. 2007; Jackson and Bruck 2013) and healthy individuals (Mills et al. 2007) with sleep disturbance have been found to have elevated levels of inflammatory markers, particularly IL-6. Specifically for women, increased inflammatory markers are also evident during pregnancy, and may be associated with pregnancy complications (Okun et al. 2007; Okun et al. 2013). It has been hypothesized that sleeping difficulties may increase the risk of depression through these inflammatory processes. 
There are also social factors that may explain this link. Insomnia is related to decreased quality of life, social and interpersonal functioning, and workplace performance, and any of these could result in levels of distress or life events that may trigger, maintain, or worsen mental health issues. It is likely that there is not a simple cause-effect relationship between sleep and mental health, but rather a bidirectional and complex interplay which may vary across time. In all of these hypotheses, treatment of insomnia is possibly a key element in the prevention of depression and anxiety later in life; our data would suggest even up to a decade later.

\section{$\underline{\text { Limitations }}$}

There are a number of limitations that are inherent to survey data, such as the self-reported nature of the data collected. In particular, reports of a mental illness diagnosis were not clinically confirmed. The survey also included a relatively broad question regarding the respondent's level of self-reported sleeping problems over the previous year. Respondents were not asked about specific insomnia symptoms (e.g. difficulties falling asleep) or whether a diagnosis of insomnia had been made. While a positive answer to this question would most likely be given by women who had insomnia or poor sleep (e.g. difficulties initiating or maintaining sleep), it may also include women who have other sleep disorders such as restless legs syndrome or hypersomnia. Therefore, these findings cannot be extrapolated to specific clinical sleep disorder such as insomnia. Future longitudinal studies would benefit from including clinical assessments of both depression and sleep disorders. There was a drop-out rate of $37 \%$ by the 2009 survey, which may have caused a selection-bias. There are also a number of other extraneous factors that may have played a role in sleeping difficulties in this cohort, including contraceptive use, child birth or rearing and family history of sleep disorders. In addition, there was a slight sample bias to 
women with higher socio-economic status, and the survey underrepresented minority groups (including indigenous and those with limited English literacy) (Lee et al. 2005). Given that there may be higher incidences of mental health concerns and sleeping problems among those in lower socio-economic and minority groups (Hall et al. 2008; Paine et al. 2004), the findings of the current study may underestimate the actual prevalence rates and risks in the Australian community. On the other hand, given the high attrition rate and self-report nature of the data, it is plausible that those respondents that were retained were those who were more engaged in the health care system, and therefore there may have been an overestimation of the risk and/or morbidity.

Future research would also benefit from determining what insomnia subtypes are most vulnerable to depression (Yokoyama et al. 2010), and whether the risk differs between those with chronic and acute insomnia. It is important to understand what neurobiological, cognitive or psychological mechanisms underlie the link between sleep disturbance and mood disorder in order to appropriately and effectively combat both conditions.

\section{Conclusion and Implications}

Self-reported frequent sleep difficulties in women aged in their early twenties, who had not experienced mental health problems previously, strongly predicted the subsequent development of depression over the next decade, with analyses yielding a four-fold risk. Similarly, selfreported sleeping problems also predicted a two-fold increased risk of anxiety. The documented relationship between sleep difficulties and depression was higher than previously reported, and twice the level of the conclusion from a meta-analysis (Baglioni et al. 2011). This may be a 
result of the population group under study - young women - who are known to be particularly susceptible to both insomnia and depression.

Preliminary evidence suggests improved outcomes in patients who are concurrently treated for depression and sleep problems (Manber et al. 2008). Treatment strategies addressing sleep difficulties could be a key preventative measure for reducing the incidence of depression in some cases, particularly in younger adults and adolescents (Clarke and Harvey 2012). Future longitudinal research examining mental health outcomes in those who have sought treatment for their sleeping problems compared to those who have not had treatment would help to confirm this hypothesis. Studies such as these highlight the importance of addressing sleeping issues within the context of mental health, and developing potential novel treatments (that include improving sleep) for reducing or even preventing mental illness. 


\section{Acknowledgements}

Dr. Jackson is funded by an Australian National Health and Medical Research Council

Fellowship.

\section{Conflict of Interest disclosure}

Dr. Jackson, Professor Byles and Professor Bruck declare that they have no conflicts of interest.

Dr. Diamond and Dr. Sztendur are the Directors of ESQANT Statistical Computing. 


\section{References}

Armitage R, Trivedi M, Hoffmann R, Rush AJ (1997) Relationship between objective and subjective sleep measures in depressed patients and healthy controls. Depression Anx 5:97-102.

Australian Longitudinal Study on Women's Health (2011) Women's Health Australia data map. http://www.alswh.org.au/images/content/pdf/InfoData/Data_Map/Data\%20Map.pdf.

Baglioni C, Battagliese G, Feige B, Spiegelhalder K, Nissen C, Voderholzer U, Lombardo C, Riemann D (2011) Insomnia as a predictor of depression: a meta-analytic evaluation of longitudinal epidemiological studies. J Affect Disord 135 (1-3):10-19

Begg S, Vos T, Barker B, Stevenson C, Stanley L, Lopez AD (2007) The burden of disease and injury in Australia 2003. AIHW, Canberra, Australia

Blackwell T, Yaffe K, Ancoli-Israel S, Schneider JL, Cauley JA, Hillier TA, Fink HA, Stone KL (2006) Poor sleep is associated with impaired cognitive function in older women: the study of osteoporotic fractures. J Gerontol Series A 61(4):405-410

Breslau N, Roth T, Rosenthal L, Andreski P (1996) Sleep disturbance and psychiatric disorders: a longitudinal epidemiological study of young adults. Biol Psychiatry 39 (6):411-418

Bruck D, Astbury J (2012) Population study on the predictors of sleeping difficulties in young Australian women. Behav Sleep Med 10 (2):84-95.

Buysse DJ, Angst J, Gamma A, Ajdacic V, Eich D, Rössler W (2008) Prevalence, course, and comorbidity of insomnia and depression in young adults. Sleep 31 (4):473-480

Byles JE, Mishra GD, Harris MA (2005) The experience of insomnia among older women. Sleep 28 (8):972-979

Byles JE, Mishra GD, Harris MA, Nair K (2003) The problems of sleep for older women: changes in health outcomes. Age Ageing 32 (2):154-163

Carr-Gregg MRC, Enderby KC, Grover SR (2003) Risk-taking behaviour of young women in Australia: screening for health-risk behaviours. Medical J Aust 178:601-604

Carskadon MA (2002) Factors influencing sleep patterns of adolescents. In: Carskadon MA (ed) Adolescent sleep patterns: Biological, social, and psychological influences. Cambridge University Press, New York, NY, US, pp 4-26.

Chang PP, Ford DE, Mead LA, Cooper-Patrick L, Klag MJ (1997) Insomnia in young men and subsequent depression. Am J Epidemiol 146 (2):105-114

Clarke G, Harvey AG (2012) The Complex Role of Sleep in Adolescent Depression. Child Adolesc Psychiatr Clin N Am 21 (2):385-400

Colrain I, Baker F (2011) Changes in sleep as a function of adolescent development. Neuropsychology Review 21 (1):5-21. doi:10.1007/s11065-010-9155-5

Dobson KS, Dozois DJ (2011) Risk factors in depression. Academic Press, San Diego, CA

Dodge R, Cline MG, Quan SF (1995) The natural history of insomnia and its relationship to respiratory symptoms. Arch Intern Med 155 (16):1797-1800

Drake C, Richardson G, Roehrs T, Scofield H, Roth T (2004) Vulnerability to stress-related sleep disturbance and hyperarousal. Sleep 27 (2):285-292

Gangwisch JE, Babiss LA, Malaspina D, Turner JB, Zammit GK, Posner K (2010) Earlier parental set bedtimes as a protective factor against depression and suicidal ideation. Sleep 33 (1):97-106 
Gillin JC (1998) Are sleep disturbances risk factors for anxiety, depressive and addictive disorders? Acta Psychiatrica Scand 98:39-43.

Hall M, Buysse DJ, Nofzinger EA, Reynolds CF, Thompson W, Mazumdar S, Monk TH (2008) Financial strain is a significant correlate of sleep continuity disturbances in late-life. Biol Psychol 77:217-222

Hillman DR, Lack L (2013) Public health implications of sleep loss: the community burden. Medical J Aust 199 (8):7-10

Jackson M, Bruck D (2012) Sleep abnormalities in Chronic Fatigue Syndrome/Myalgic Encephalomyelitis: A review. J Clin Sleep Med 8:719-728

Jansson-Fröjmark M, Lindblom K (2008) A bidirectional relationship between anxiety and depression, and insomnia? A prospective study in the general population. J Psychosom Res 64 (4):443-449.

Jorm AF (2000) Does old age reduce the risk of anxiety and depression? A review of epidemiological studies across the adult life span. Psychological Medicine 30 (1):11-22

Lee C, Dobson AJ, Brown WJ, Bryson L, Byles J, Warner-Smith P, Young AF (2005) Cohort profile: The Australian Longitudinal Study on Women's Health. Int J Epidemiol 34:987991

Leineweber C, Kecklund G, Janszky I, Akerstedt T, Orth-Gomer K (2003) Poor sleep increases the prospective risk for recurrent events in middle-aged women with coronary disease: the Stockholm Female Coronary Risk Study. J Psychosom Res 54(2):121-127

Majde JA, Krueger JM (2005) Links between the innate immune system and sleep. J Allergy Clin Immunol 116:1188-1198

Manber R, Edinger JD, Gress JL, San Pedro-Salcedo MG, Kuo TF, Kalista T (2008) Cognitive behavioral therapy for insomnia enhances depression outcome in patients with comorbid major depressive disorder and insomnia. Sleep 31 (4):489-495

Mills PJ, von Känel R, Norman D, Natarajan L, Ziegler MG, Dimsdale JE (2007) Inflammation and sleep in healthy individuals. Sleep 30:729-735

Motivala SJ, Sarfatti A, Olmos L, Irwin MR (2005) Inflammatory markers and sleep disturbance in major depression. Psychosom Med 67:187-194

Murray CJL, Lopez AD (1997) Alternative projections of mortality and disability by cause 19902020: Global Burden of Disease Study. Lancet 349 (9064):1498-1504

Neckelmann D, Mykletun A, Dahl AA (2007) Chronic insomnia as a risk factor for developing anxiety and depression. Sleep 30 (7):873-880

Novati A, Roman V, Cetin T, Hagewoud R, Den Boer JA, Luiten PGM, Meerlo P (2008) Chronically restricted sleep leads to depression-like changes in neurotransmitter receptor sensitivity and neuroendocrine stress reactivity in rats. Sleep 31 (11):1579-1585

Ohayon MM (2002) Epidemiology of insomnia: what we know and what we still need to learn. Sleep Med Rev 6 (2):97-111

Ohayon MM, Reynolds CF (2009) Epidemiological and clinical relevance of insomnia diagnosis algorithms according to the DSM-IV and the International Classification of Sleep Disorders (ICSD). Sleep Med 10 (9):952-960. Okun ML, Hall M, Coussons-Read ME (2007) Sleep disturbances increase Interleukin-6 production during pregnancy: implications for pregnancy complications. Reproductive Sci 14:560-567

Okun ML, Luther JF, Wisniewski SR, Wisner KL (2013) Disturbed sleep and inflammatory cytokines in depressed and nondepressed pregnant women: an exploratory analysis of pregnancy outcomes. Psychosom Med 75:670-681 
Paine SJ, Gander PH, Harris R, Reid P (2004) Who reports insomnia? Relationships with age, sex, ethnicity and socio-economic deprivation. Sleep 27:1163-1169

R Development Core Team (2008). R: A language and environment for statistical computing. $R$ Foundation for Statistical Computing, Vienna, Austria. ISBN 3-900051-07-0, URL http://www.R-project.org.

Roane BM, Taylor DJ (2008) Adolescent insomnia as a risk factor for early adult depression and substance abuse. Sleep 31 (10):1351-1356

Roberts RE, Duong HT (2013) Depression and insomnia among adolescents: A prospective perspective. Journal of Affective Disorders 148:66-71

Roberts RE, Ramsay Roberts C, Ger Chen I (2002) Impact of insomnia on future functioning of adolescents. J Psychosom Res 53 (1):561-569

Roberts RE, Shema SJ, Kaplan GA, Strawbridge WJ (2000) Sleep complaints and depression in an aging cohort: a prospective perspective. Am J Psychiatry 157 (1):81-88

Salo P, Sivertsen B, Oksanen T, Sjösten N, Pentti J, Virtanen M, Kivimäki M, Vahtera J (2012) Insomnia symptoms as a predictor of incident treatment for depression: Prospective cohort study of 40,791 men and women. Sleep Med 13:278-284

Shochat T, Flint-Bretler O, Tzischinsky O (2010) Sleep patterns, electronic media exposure and daytime sleep-related behaviours among Israeli adolescents. Acta Pædiatrica 99 (9):13961400

Spasojević J, Alloy LB (2001) Rumination as a common mechanism relating depressive risk factors to depression. Emotion 1 (1):25-37

Szklo-Coxe M, Young T, Peppard PE, Finn LA, Benca RM (2010) Prospective associations of insomnia markers and symptoms with depression. Am J Epidemiol 171 (6):709-720

Van Buuren S, Groothius-Oudshoorn K (2011) MICE: Multivariate Imputation by Chained Equations in R. J Statistical Software 43 (3):1-67

Watson NF, Harden KP, Buchwald D, Vitiello MV, Pack AI, Strachan E, Goldberg J (2014) Sleep duration and depressive symptoms: a gene-environment interaction. Sleep 37(2):351-358

Weissman MM, Greenwald S, Niño-Murcia G, Dement WC (1997) The morbidity of insomnia uncomplicated by psychiatric disorders. Gen Hosp Psychiatry 19 (4):245-250.

Wittchen H-U, Knäuper B, Kessler RC (1994) Lifetime risk of depression. Br J Psychiatry 165 (26): $16-22$

Yokoyama E, Kaneita Y, Saito Y, Uchiyama M, Matsuzaki Y, Tamaki T, Munezawa T, Ohida T (2010) Association between depression and insomnia subtypes: a longitudinal study on the elderly in Japan. Sleep 33 (12):1693-1702

Yoo S-S, Gujar N, Hu P, Jolesz FA, Walker MP (2007) The human emotional brain without sleep -- a prefrontal amygdala disconnect. Curr Biol 17 (20):R877-R878 
Fig. 1 Percentage of women who reported antidepressant use (black bars) among women with depression (grey bars), as a function of sleeping difficulty frequency. The 2009 survey did not include a question regarding antidepressant use, therefore this data is not available for this survey. Note: All the above graphs exclude women who, in 2000, reported a previous mental health diagnosis, symptoms of anxiety or depression in past 12 months, and/or antidepressant use. 


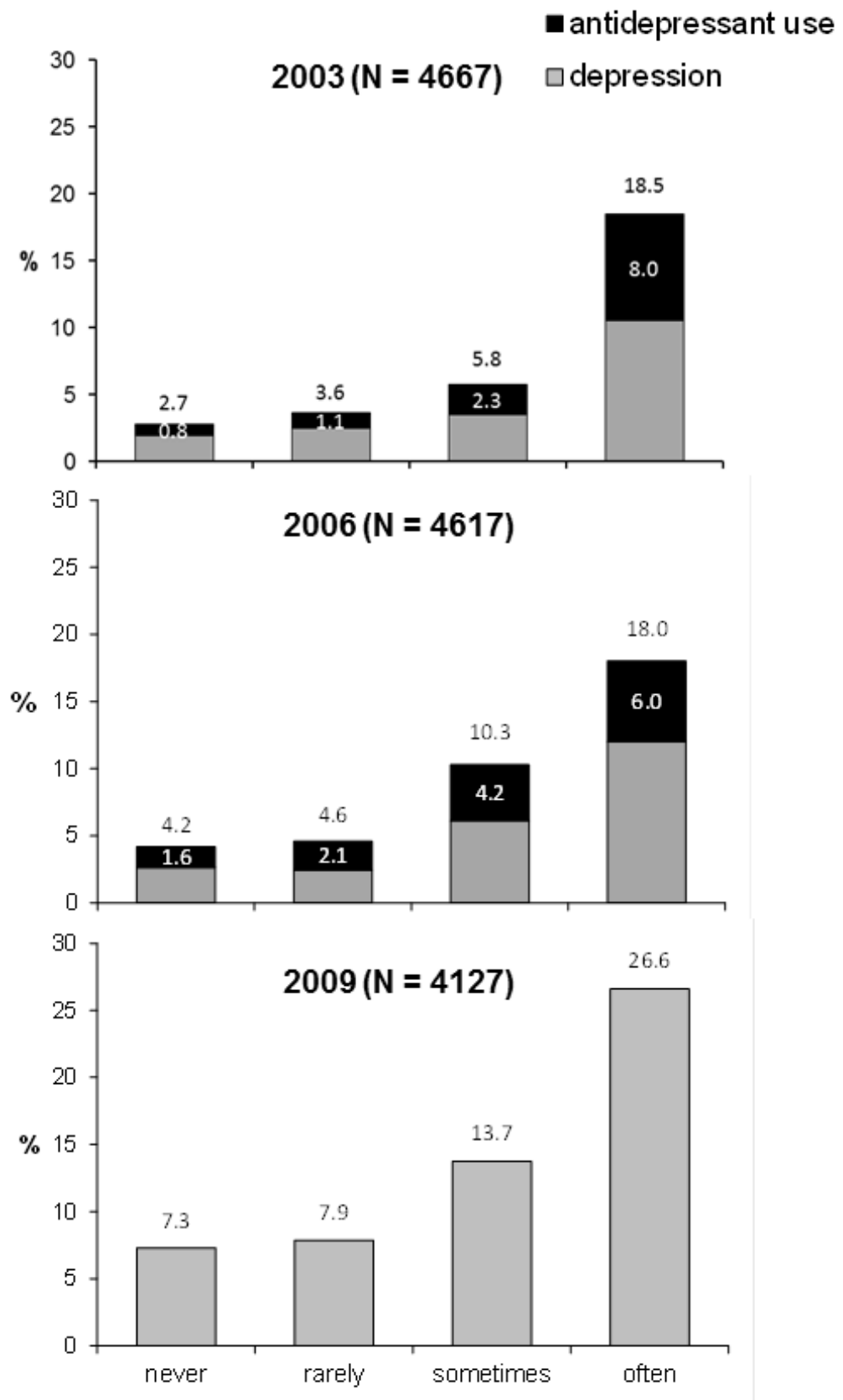


Table I Sample characteristics in $2000(\mathrm{~N}=9683)$.

\begin{tabular}{|c|c|c|c|}
\hline & $\mathrm{N}$ & $\%$ & Valid \% \\
\hline \multicolumn{4}{|l|}{ Marital status } \\
\hline Never married & 7045 & 72.8 & 73.3 \\
\hline Married & 2361 & 24.4 & 24.6 \\
\hline Separated/Divorced & 196 & 2.0 & 2.0 \\
\hline Widowed & 5 & 0.1 & 0.1 \\
\hline No response & 76 & 0.8 & \\
\hline \multicolumn{4}{|l|}{ Highest education } \\
\hline No formal education & 144 & 1.5 & 1.5 \\
\hline Year 10 or equivalent & 907 & 9.4 & 9.7 \\
\hline Year 12 or equivalent & 2251 & 23.2 & 24.1 \\
\hline Trade/apprenticeship & 293 & 3.0 & 3.1 \\
\hline Certificate/diploma & 1974 & 20.4 & 21.2 \\
\hline University degree & 3204 & 33.1 & 34.3 \\
\hline Higher university degree & 560 & 5.8 & 6.0 \\
\hline No response & 350 & 3.6 & \\
\hline \multicolumn{4}{|l|}{ Occupation } \\
\hline Manager/administrator & 458 & 4.7 & 5.0 \\
\hline Professional & 3249 & 33.6 & 35.8 \\
\hline Associate professional & 594 & 6.1 & 6.5 \\
\hline Tradeperson & 332 & 3.4 & 3.7 \\
\hline Clerical/service worker & 3118 & 32.2 & 34.3 \\
\hline Intermediate production or transport worker & 50 & 0.5 & 0.6 \\
\hline Labourer & 344 & 3.6 & 3.8 \\
\hline No paid job & 941 & 9.7 & 10.4 \\
\hline No Response & 597 & 6.2 & \\
\hline \multicolumn{4}{|l|}{ Medication for nerves } \\
\hline Yes & 161 & 1.7 & 1.7 \\
\hline No & 9250 & 95.5 & 98.3 \\
\hline No response & 272 & 2.8 & \\
\hline \multicolumn{4}{|l|}{ Medication for sleep } \\
\hline Yes & 242 & 2.5 & 2.6 \\
\hline No & 9169 & 94.7 & 97.4 \\
\hline No response & 272 & 2.8 & \\
\hline \multicolumn{4}{|l|}{ Medication for depression } \\
\hline Yes & 427 & 4.4 & 4.5 \\
\hline No & 8984 & 92.8 & 95.5 \\
\hline No response & 272 & 2.8 & \\
\hline \multicolumn{4}{|l|}{ Binge drinking } \\
\hline Do not drink alcohol & 858 & 8.9 & 9.0 \\
\hline Never & 1828 & 18.9 & 19.1 \\
\hline Less than once a month & 3583 & 37.0 & 37.5 \\
\hline About once a month & 1931 & 19.9 & 20.2 \\
\hline About once a week & 1192 & 12.3 & 12.5 \\
\hline More than once a week & 174 & 1.8 & 1.8 \\
\hline No response & 117 & 1.2 & \\
\hline \multicolumn{4}{|l|}{ Body weight dissatisfaction } \\
\hline Happy as I am/<10kg more $/<10 \mathrm{~kg}$ less & 7917 & 81.8 & 82.9 \\
\hline Over $10 \mathrm{~kg}$ less & 1632 & 16.9 & 17.1 \\
\hline No response & 134 & 1.4 & \\
\hline \multicolumn{4}{|l|}{ History of abuse } \\
\hline Yes & 3717 & 38.4 & 39.0 \\
\hline No & 5589 & 57.7 & 58.6 \\
\hline Don't want to answer & 230 & 2.4 & 2.4 \\
\hline No response & 147 & 1.5 & \\
\hline
\end{tabular}


Table II Cross-sectional prevalence (\%) of sleeping difficulties, mental health diagnoses, and depression and anxiety symptoms of the study sample at each survey

\begin{tabular}{|c|c|c|c|c|c|c|c|c|}
\hline & \multicolumn{2}{|c|}{$2000(N=9683)$} & \multicolumn{2}{|c|}{$2003(\mathrm{~N}=9078)$} & \multirow{2}{*}{$\frac{2006}{\mathrm{~N}}$} & \multirow{2}{*}{$\begin{array}{c}(\mathbf{N}=\mathbf{9 1 4 0}) \\
\%\end{array}$} & \multicolumn{2}{|c|}{$2009(\mathrm{~N}=8196)$} \\
\hline & $\mathrm{N}$ & $\%$ & $\mathrm{~N}$ & $\%$ & & & $\mathrm{~N}$ & $\%$ \\
\hline \multicolumn{9}{|c|}{ Depression Diagnosis in last 3 years } \\
\hline Yes & 1114 & 11.6 & 1124 & 12.6 & 1162 & 13.5 & 1338 & 17.7 \\
\hline No & 8466 & 88.4 & 7808 & 87.4 & 7445 & 86.5 & 6227 & 82.3 \\
\hline No Response & 103 & & 146 & & 533 & & 631 & \\
\hline \multicolumn{9}{|c|}{ Anxiety Diagnosis in last 3 years } \\
\hline Yes & 453 & 4.7 & 545 & 6.1 & 623 & 7.2 & 753 & 10.0 \\
\hline No & 9127 & 95.3 & 8387 & 93.9 & 7984 & 92.8 & 6812 & 90.0 \\
\hline No Response & 103 & & 146 & & 533 & & 631 & \\
\hline \multicolumn{9}{|c|}{ Comorbid Diagnoses in last 3 years } \\
\hline Depression Only & 835 & 8.7 & 790 & 8.8 & 784 & 9.1 & 825 & 10.9 \\
\hline Anxiety Only & 174 & 1.8 & 211 & 2.4 & 245 & 2.8 & 240 & 3.2 \\
\hline Both & 279 & 2.9 & 334 & 3.7 & 378 & 4.4 & 513 & 6.8 \\
\hline Neither & 8292 & 86.6 & 7597 & 85.1 & 7200 & 83.7 & 5987 & 79.1 \\
\hline No Response & 103 & & 146 & & 533 & & 631 & \\
\hline \multicolumn{9}{|c|}{ Sleeping Difficulties in last 3 years } \\
\hline Never & 5882 & 60.9 & 4427 & 48.9 & 3851 & 42.5 & 3524 & 43.6 \\
\hline Rarely & 1042 & 10.8 & 1771 & 19.6 & 2025 & 22.3 & 1720 & 21.3 \\
\hline Sometimes & 1762 & 18.2 & 2020 & 22.3 & 2223 & 24.5 & 1956 & 24.2 \\
\hline Often & 980 & 10.1 & 835 & 9.2 & 965 & 10.6 & 878 & 10.9 \\
\hline No Response & 17 & & 25 & & 76 & & 118 & \\
\hline \multicolumn{9}{|c|}{ Depression Symptoms in last 12 months } \\
\hline Never & 6675 & 69.1 & 5817 & 64.3 & 5836 & 64.5 & 5152 & 63.8 \\
\hline Rarely & 1014 & 10.5 & 1349 & 14.9 & 1348 & 14.9 & 1234 & 15.3 \\
\hline Sometimes & 1324 & 13.7 & 1334 & 14.7 & 1297 & 14.3 & 1144 & 14.2 \\
\hline Often & 653 & 6.8 & 553 & 6.1 & 564 & 6.2 & 544 & 6.7 \\
\hline No Response & 17 & & 25 & & 96 & & 122 & \\
\hline \multicolumn{9}{|c|}{ Anxiety Symptoms in last 12 months } \\
\hline Never & 7875 & 81.5 & 7253 & 80.1 & 7119 & 78.7 & 6281 & 77.8 \\
\hline Rarely & 973 & 10.1 & 986 & 10.9 & 1103 & 12.2 & 1019 & 12.6 \\
\hline Sometimes & 593 & 6.1 & 590 & 6.5 & 609 & 6.7 & 584 & 7.2 \\
\hline Often & 225 & 2.3 & 224 & 2.5 & 214 & 2.4 & 190 & 2.4 \\
\hline No Response & 17 & & 25 & & 95 & & 122 & \\
\hline
\end{tabular}

$\%$ - valid percentage of total responders at each survey

$\wedge$ In past 4 years for the 2000 survey 
Table III Adjusted and unadjusted models for the association between sleeping difficulties in 2000 and self-reported depression diagnosis at each follow up survey $(\mathrm{N}=5702)$.

\begin{tabular}{llcccccc}
\hline Depression & Sleeping Difficulty & \multicolumn{3}{c}{ Model 1 } & \multicolumn{4}{c}{ Model 2 } \\
Diagnosis & in 2000 & OR & $95 \%$ CI & & OR & $95 \%$ & CI \\
\hline 2003 & Never & 1.00 & & & 1.00 & & \\
& Rarely & 1.10 & 0.62 & 1.93 & 1.07 & 0.61 & 1.89 \\
& Sometimes & $\mathbf{1 . 9 2}$ & 1.33 & 2.79 & $\mathbf{1 . 8 1}$ & 1.24 & 2.64 \\
& Often & $\mathbf{2 . 6 4}$ & 1.63 & 4.29 & $\mathbf{2 . 3 0}$ & 1.50 & 3.78 \\
& & & & & & & \\
2006 & Never & $\mathbf{1 . 5 2}$ & 1.15 & 1.94 & $\mathbf{1 . 5 3}$ & 1.20 & 1.95 \\
& Rarely & $\mathbf{2 . 4 7}$ & 1.62 & 3.43 & $\mathbf{2 . 2 6}$ & 1.48 & 3.43 \\
& Sometimes & $\mathbf{2 . 5 2}$ & 1.72 & 3.41 & $\mathbf{2 . 2 8}$ & 1.60 & 3.25 \\
& Often & $\mathbf{4 . 4 0}$ & 2.86 & 6.98 & $\mathbf{4 . 2 1}$ & 2.82 & 6.28 \\
& & & & & & & \\
2009 & Never & $\mathbf{2 . 5 7}$ & 2.08 & 3.16 & $\mathbf{2 . 5 9}$ & 2.10 & 3.20 \\
& Rarely & $\mathbf{2 . 4 1}$ & 1.56 & 3.73 & $\mathbf{2 . 4 0}$ & 1.55 & 3.74 \\
& Sometimes & $\mathbf{3 . 4 3}$ & 2.49 & 4.74 & $\mathbf{3 . 2 8}$ & 2.37 & 4.54 \\
& Often & $\mathbf{4 . 4 2}$ & 2.81 & 6.96 & $\mathbf{3 . 9 4}$ & 2.49 & 6.22 \\
& & & & & & & \\
& Lower education level & & & & 0.78 & 0.71 & 0.85 \\
& Body weight dissatisfaction & & & & $\mathbf{1 . 0 3}$ & 0.99 & 1.07 \\
& Binge drinking & & & & 1.00 & 0.99 & 1.00 \\
& History of abuse & & & & $\mathbf{1 . 1 6}$ & 1.10 & 1.22 \\
\hline
\end{tabular}

OR, Odd Ratio; CI, confidence interval. Significant ORs are in bold Model 1 crude

Model 2 adjusted for education level, body weight dissatisfaction, history of abuse and binge drinking in 2000 
Table IV Adjusted and unadjusted models for the association between sleeping difficulties in 2000 and self-reported anxiety diagnosis in each follow-up survey $(\mathrm{N}=5702)$.

\begin{tabular}{|c|c|c|c|c|c|c|c|}
\hline \multirow{2}{*}{$\begin{array}{l}\text { Anxiety } \\
\text { Diagnosis }\end{array}$} & \multirow{2}{*}{$\begin{array}{l}\text { Sleeping difficulty } \\
\text { frequency in } 2000\end{array}$} & \multicolumn{3}{|c|}{ Model 1} & \multicolumn{3}{|c|}{ Model 2} \\
\hline & & OR & $95^{\circ}$ & $\mathrm{CI}$ & OR & & $\mathrm{CI}$ \\
\hline & Never & 1 & & & 1 & & \\
\hline & Rarely & 1.08 & 0.52 & 2.24 & 1.05 & 0.51 & 2.19 \\
\hline & Sometimes & 2.05 & 1.36 & 3.11 & 2.05 & 1.29 & 2.97 \\
\hline & Often & 1.48 & 0.74 & 2.97 & 1.48 & 0.65 & 2.65 \\
\hline \multirow[t]{4}{*}{2006} & Never & 1.32 & 0.97 & 1.79 & 1.32 & 0.97 & 1.80 \\
\hline & Rarely & 1.93 & 1.08 & 3.44 & 1.89 & 1.06 & 3.37 \\
\hline & Sometimes & 1.85 & 1.10 & 3.11 & 1.76 & 1.04 & 2.97 \\
\hline & Often & 2.39 & 1.32 & 4.33 & 2.13 & 1.18 & 3.86 \\
\hline \multirow[t]{8}{*}{2009} & Never & 2.15 & 1.59 & 2.90 & 2.16 & 1.60 & 2.91 \\
\hline & Rarely & 2.42 & 1.39 & 4.21 & 2.37 & 1.36 & 4.13 \\
\hline & Sometimes & 2.97 & 1.89 & 4.66 & 2.83 & 1.80 & 4.46 \\
\hline & Often & 2.90 & 1.63 & 5.16 & 2.58 & 1.45 & 4.59 \\
\hline & Lower education level & & & & 0.87 & 0.77 & 0.97 \\
\hline & Body weight dissatisfaction & & & & 1.00 & 0.95 & 1.06 \\
\hline & Binge drinking & & & & 1.00 & 0.98 & 1.01 \\
\hline & History of abuse & & & & 1.18 & 1.10 & 1.28 \\
\hline
\end{tabular}

OR, Odd Ratio; CI, confidence interval. Significant ORs are in bold Model 1 crude

Model 2 adjusted for education level, body weight dissatisfaction, history of abuse and binge drinking in 2000 